\title{
Research on the risk of PFI model of endowment real estate based on Bayesian network
}

\author{
FANG Xiang-hong ${ }^{1,}$ a, YANG Zhan-she Z, b $^{2}$ \\ ${ }^{1}$ School of Management, Xi'an University of Architecture and Technology, Xian 710055, \\ China \\ ${ }^{2}$ School of Management, Xi'an University of Architecture and Technology, Xian 710055, \\ China \\ a745527473@qq.com, b1284679295@qq.com
}

Keywords: Real estate, PFI model, Bayesian Network, risk Analysis.

\begin{abstract}
The problem of the aging of population in China has gradually emerged. In the process of solving this problem, financing is an important factor to restrict the development of the real estate. Based on the use of PFI model building of endowment real estate, this paper will using the Bayesian Network to build a model of risk assessment through the identification of their risks. This method constructs the risk topology model by identifying the risk factors and the relationship among the risk factors. We'll use Bias's forward reasoning technology to predict the risk possibility and use the inverse diagnostic reasoning analyze identified risk factors when the risk happened. The application of this method has certain guidance.
\end{abstract}

\section{Introduction}

Under the background of rising elderly population in China, the problem of supplying pension services has been more serious. There are many domestic large enterprises have gradually begun to developing pension real estate. But financing is an important factor to restrict the development of the real estate, causing of the large amount of upfront investment and the longer payback periods. At present, commonly used mode of project financing: BOT, TOT, PPP, ABS, PFI are widely researched in many fields. From the aspects of the scope of risk-taking, the perspective of comparative investors, sources of funds and asset utilization efficiency, using the PFI project financing in pension real estate development exhibits many advantages [1]. Domestic research on PFI model, mainly in the conception and application fields combined with China's macro environment. The research of PFI project risk are as follow, Du Jing and Wang Xiaodong established the risk assessment model by the way of fuzzy comprehensive evaluation [2]; Jin Na and Yang Naining analyzed the feasibility of PFI financing mode in infrastructure fields by multiple attribute comprehensive evaluation of wavelet network models[3]; Zhao Yu, Liu Hang made a quantitative analysis for the feasibility of PFI financing mode in Public housing area, using analytic hierarchy process (AHP) and grey clustering analysis methods[4]. The above methods evaluated the PFI financing mode risk from the perspective of qualitative and quantitative. Those methods mostly focused on the importance of risk.

PFI financing mode are Launched by the government and operated by the special project company. It is complexity and uncertainty. When we make a quantitative evaluation of overall risks, it is not accurate that ignore the relationship between variables as independent variables. In recent years, the application of Bayesian network gradually expanded to engineering management. Areas of application includes: engineering designing, engineering construction fields, etc. The advantages of Bayesian network are reflected in its objective and accurate by synthesizing prior knowledge and experience. 


\section{PFI model of endowment real estate risk assessment}

\subsection{Bias Network Overview}

Bayesian Network, based on Bias theorem, analyze risk events by probabilistic reasoning which is uncertainties and interdependence. It includes a directed acyclic graph and node conditional probability (CPT). The joint probability distribution is as follows:

$$
p\left(x_{1} \ldots x_{n}\right)=\prod_{i=1}^{n} p\left(x_{i} \mid \operatorname{Parent}\left(X_{i}\right)\right)
$$

Any node variable changed in the network, will spread to the entire network and update the other variable's data parameters.

Forward reasoning: If $P\left(A_{i}\right)$ and $P\left(R / A_{i}\right)$, then

$$
P(R)=\sum_{i=1}^{n} P\left(R A_{i}\right)=\prod_{i=1}^{n} P(A i) P(R / A i)
$$

Backward reasoning: If $P\left(A_{i}\right)$ and $P\left(R / A_{i}\right)$, then

$$
P(A i / R)=\frac{P(R / A i) P(A i)}{\sum_{j=1}^{n} P(R / A j) P(A j)}
$$

\subsection{Risk identification and determination}

According to the theoretical researches of PFI projects, we can divide project risk into environmental risk and self risk combined PPP and PFI projects case study. Environmental Risk contains political risk, legal risk and financial risk, and the risk of natural force majeure reflected in project completion risk. The project self risk is reflected in completion risk and operational risk. Combined with domestic scholar's research for PPP project, we can get the Bayesian network index

\begin{tabular}{|c|c|c|}
\hline $\begin{array}{l}\text { First level } \\
\text { indicator }\end{array}$ & secondary index layer & three index layer \\
\hline \multirow{7}{*}{ Political risk(A) } & Government intervention(X1) & \\
\hline & & Deferred payment(X2) \\
\hline & Government credit(M1) & Negative treatment(X3) \\
\hline & & Project nationalization (X4) \\
\hline & & Land acquisition(X5) \\
\hline & Project approval(M2) & Design approval(X6) \\
\hline & & Construction project approval (X7) \\
\hline & Political force majeure (X8) & \\
\hline Legal risk & Imperfect legal system(X9) & \\
\hline (B) & Industrial investment policy changes(X10) & \\
\hline $\begin{array}{l}\text { Financial risk } \\
\text { (C) }\end{array}$ & $\begin{array}{c}\text { Interest rate change (X11) } \\
\text { Inflation(X12) }\end{array}$ & \\
\hline \multirow{7}{*}{$\begin{array}{l}\text { Completion risk } \\
\text { (D) }\end{array}$} & Financing risk(M3) & $\begin{array}{c}\text { Instability in financial markets(X13) } \\
\text { Irrational financing structure (X14) }\end{array}$ \\
\hline & Design risk(M4) & $\begin{array}{l}\text { Technology design(X15) } \\
\text { Contract design(X16) }\end{array}$ \\
\hline & & Investors change(X17) \\
\hline & Risk of project organization(MЬ) & Organization coordination risk(X18) \\
\hline & & Whether the supply of resources is sustainable (X19) \\
\hline & Construction risk(M6) & Construction change(X20) \\
\hline & & Force majeure(X21) \\
\hline \multirow{4}{*}{$\begin{array}{l}\text { Operational } \\
\operatorname{risk}(\mathrm{E})\end{array}$} & $\begin{array}{l}\text { Advanced management and experience } \\
\text { accumulation (X22) }\end{array}$ & \multirow{4}{*}{$\begin{array}{l}\text { Market risk(X23) } \\
\text { Pricing risk(X24) }\end{array}$} \\
\hline & Market environment(M7) & \\
\hline & varket environment(1v/) & \\
\hline & $\begin{array}{l}\text { Resource sustainability(X25) } \\
\text { Maintenance risk(X26) }\end{array}$ & \\
\hline
\end{tabular}
system of risk management. Be shown in Table 1.

Table 1: Pension estate PFI project risk list 


\subsection{Building the Bayesian network model}

The project risk factors of logical relationship are clear, so we can determine the causal relationship between risk factors by organize expert's experience and knowledge. Then, build the projects risk management structure model by the analysis software GenIe2.0. Be shown in Fig. 1.

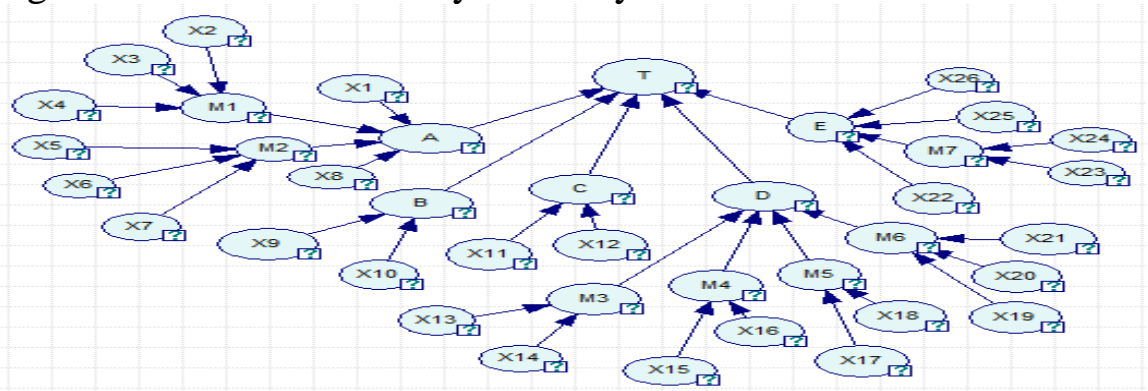

Fig. 1: Pension Real Estate PFI mode risk Bayesian Network Diagram

Due to the lack of information and data in this field are inadequate, we can determine the parameters for the network nodes by Prior knowledge of experts. And use AHP method to determine the weight of the invited experts from the aspects of technical titles, academic standards, professional ethics, research expertise, previous evaluation of the quality and experience.

Risk assessment evaluation methods commonly used are as follows: $R(X)=P(X) \times C(X)$

$\mathrm{R}(\mathrm{X})$ represents the probability of the risk events, $\mathrm{P}(\mathrm{X})$ indicates the occurrence of risk factors Level, C (X) indicates the severity of risk factors. Grading principles are as follows in Table 2:

Table 2: The risk level and severity

\begin{tabular}{cccccc}
\hline & Risk level & \multicolumn{3}{c}{ Risk severity } \\
\hline Description & level & $\begin{array}{c}\text { Probability } \\
\text { of } \\
\text { occurrence }\end{array}$ & Description & level & $\begin{array}{c}\text { Probability of } \\
\text { occurrence }\end{array}$ \\
Almost & 1 & 0.1 & General level & A & 0.1 \\
impossible & 2 & 0.3 & Not too serious & B & 0.3 \\
very seldom & 2 & 0.5 & More serious & C & 0.5 \\
Accidental & 3 & 0.7 & Serious & D & 0.7 \\
Sometimes & 4 & 0.9 & Very serious & E & 0.9 \\
Often & 5 & & & \\
\hline
\end{tabular}

\subsection{Bayesian Network risk assessment}

After parameter determination is completed, put the data into network diagram. We can get the degree of influence between nodes by the following equation.

$P(A / B)=\frac{P(B / A) P(A)}{P(B)}$

\section{Case analysis of financing}

A pension real estate projects, including the construction of senior housing, elderly health, rehabilitation centers, cultural and entertainment centers, markets and other functional areas, with a total area of 110,551 square meters, total investment of over 800 million $¥$. Urban residents per capita disposable income is about 18,619 $¥$ in 2015. Urban resident population is about 8 million while about $10 \%$ people are over 60 years old. Next, make a risk assessment for the city's PFI pension real estate projects.

Set those various risk factors identified in Table 1 to the network node. Then, invite several expert score for the nodes and multiplied by the expert weight to get the resulting probability. Shown in Table 3: 
Table 3: Prior probability and posterior probability of the root

\begin{tabular}{|c|c|c|c|c|c|c|c|c|c|}
\hline $\begin{array}{c}\text { Variab } \\
\text { les }\end{array}$ & $\begin{array}{c}\text { The } \\
\text { possibility of } \\
\text { occurrence }\end{array}$ & $\begin{array}{c}\text { The } \\
\text { severity of } \\
\text { the } \\
\text { occurrenc } \\
\mathrm{e}\end{array}$ & $\begin{array}{c}\text { Occurring } \\
\text { probabilit } \\
\mathrm{y}\end{array}$ & $\begin{array}{c}\text { Posterior } \\
\text { probabilit } \\
\mathrm{y}\end{array}$ & $\begin{array}{c}\text { Variabl } \\
\text { es }\end{array}$ & $\begin{array}{c}\text { The } \\
\text { possibility } \\
\text { of } \\
\text { occurrence }\end{array}$ & $\begin{array}{c}\text { The } \\
\text { severity of } \\
\text { the } \\
\text { occurrenc } \\
\mathrm{e}\end{array}$ & $\begin{array}{c}\text { Occurring } \\
\text { probabilit } \\
\mathrm{y}\end{array}$ & $\begin{array}{c}\text { Posterior } \\
\text { probabilit }\end{array}$ \\
\hline$X_{1}$ & 0.65 & 0.72 & 0.468 & 0.499 & $X_{14}$ & 0.53 & 0.83 & 0.440 & 0.434 \\
$X_{2}$ & 0.31 & 0.54 & 0.167 & 0.168 & $X_{15}$ & 0.66 & 0.69 & 0.455 & 0.444 \\
$X_{3}$ & 0.22 & 0.75 & 0.165 & 0.167 & $X_{16}$ & 0.65 & 0.66 & 0.429 & 0.433 \\
$X_{4}$ & 0.13 & 0.81 & 0.105 & 0.107 & $X_{17}$ & 0.55 & 0.47 & 0.259 & 0.274 \\
$X_{5}$ & 0.42 & 0.66 & 0.277 & 0.281 & $X_{18}$ & 0.53 & 0.36 & 0.191 & 0.195 \\
$X_{6}$ & 0.40 & 0.42 & 0.168 & 0.169 & $X_{19}$ & 0.35 & 0.53 & 0.186 & 0.186 \\
$X_{7}$ & 0.43 & 0.46 & 0.198 & 0.200 & $X_{20}$ & 0.52 & 0.45 & 0.234 & 0.233 \\
$X_{8}$ & 0.1 & 0.73 & 0.073 & 0.074 & $X_{21}$ & 0.15 & 0.72 & 0.108 & 0.107 \\
$X_{9}$ & 0.51 & 0.62 & 0.316 & 0.341 & $X_{22}$ & 0.63 & 0.81 & 0.510 & 0.516 \\
$X_{10}$ & 0.46 & 0.79 & 0.363 & 0.390 & $X_{23}$ & 0.60 & 0.72 & 0.432 & 0.439 \\
$X_{11}$ & 0.43 & 0.55 & 0.237 & 0.260 & $X_{24}$ & 0.37 & 0.55 & 0.201 & 0.204 \\
$X_{12}$ & 0.46 & 0.42 & 0.193 & 0.229 & $X_{25}$ & 0.30 & 0.43 & 0.129 & 0.129 \\
$X_{13}$ & 0.31 & 0.51 & 0.158 & 0.145 & $X_{26}$ & 0.57 & 0.62 & 0.353 & 0.390 \\
\hline
\end{tabular}

Input those nota data into PFI pension estate of risk assessment model build by software GenIe2.0. After the parameters learning, operate the network, we can get the finial risk probability that $\mathrm{P}(\mathrm{T})=45.1 \%$. Based on the risk probability, enterprises make a business investment decisions by amend the network node parameters according to their own advantages and resources to control the degree of risks.

Order Bayesian network $\mathrm{P}(\mathrm{T})=1$, posterior probability of all root can be obtained for its backward diagnostic technology. The results shown in table 3. Sort by posterior probability, we select the top 5 risks which are X22(Advanced and experience of managers), X1 (government intervention), X15 (technical design), X23 (financing structure), X14 (industrial investment policy).Posterior probability values were $0.516,0.499,0.444,0.439$ and 0.434 .

\section{Conclusions and suggestion}

The development of the real estate industry, the management ability and management experience of the private enterprise directly determines the success of the project. The policy environment provided by the government is related to the risk of private enterprises. With efficient financing structure and sustainable capital flow, it is the guarantee of private enterprises to obtain sustainable resources in the course of project construction operation. At the same time, the technical design of the project construction stage has great influence on the project completion and service supply。This paper puts forward suggestions for the government and private organizations.

On the government level, the government should make a fair legal provision, on the one hand, can guarantee the project smoothly, on the other hand also ensures the interests of investors and improve the social capital to enter the real estate. Provide preferential financing policies for the private sector, can reduce the risk of financing, such as reducing the cost of land development, as well as to provide security for the loan bank. Pension real estate in a property also belongs to the public. Therefore, in terms of market access and charges, fees and taxes, the government can also increase policy support. The design of the contract requires the reasonable allocation of risks between the government and the participants in order to realize the balance of the interests of the main body. In order to cope with the changing market environment, it is necessary to make up for the lack of investors' income, The model of the bundle type can be used in the project development phase, after the end of the project franchise period, the government can decide whether to extend the operating period and so on. 
Private enterprises should strengthen the industry innovation research. Learn from the excellent construction operation mode. Improve the operating efficiency of the project by improving the quality of service and operational efficiency of the pension service. Such as selection of dynamic alliance of enterprises can not only make up the deficiency of traditional enterprises in technology, human resources, capital and other aspects, but also can enhance the enterprise's comprehensive competitiveness, organization and management efficiency and market adaptability.

\section{Reference}

[1] Liu Yufeng, Li Zhengwei, Zhang Qi. Risk sharing research based on the PFI financing model of endowment real estate [J]. Chinese real estate, 2012, 12: 62-66.

[2] Du Jing, Wang Xiaodong. Evaluation of the PFI project risks based on the Fuzzy Comprehensive Evaluation method [J] blur building economic, 2008, S1: 304-308.

[3] Jin Na, Yang Naiding, Gao Qian. Risk analysis of regional investment in infrastructure projects based on PFI model [J]. Soft Science, 2007, 01: 10-13.

[4] Zhao Yu, Liu Hang, Xu Jiaxin, Zhou Lei. Risk evaluation method of public rental housing construction based on analytic hierarchy process and grey clustering PFI model [J]. Journal of Engineering Management, 2013, 01: 69-72. 